\title{
Recognition of Prior Learning for Master Marine with Indonesian Qualifications Framework
}

\author{
Antoni Arif Priadi, Tri Cahyadi, Damoyanto Purba \\ Nautical Study \\ Jakarta, Indonesia \\ antoni.pip.smg@gmail.com
}

\author{
Novita Vindri Harini, Zainullah Zuhri \\ Universitas Islam Negeri Sunan Ampel \\ Surabaya, Indonesia
}

\begin{abstract}
A master Mariner is a professional person who has highest level of knowledge and experiences in ship operation from planning, executing, managing, analyzing and evaluating. The Indonesian Qualification Framework gives the opportunities professional like a Master Mariner to be equalized within a certain level of framework based on their knowledge and experience. This paper is organized to analyze the recognition of a Master Mariner into Indonesian Qualification Framework through the literature and content analysis and the formulation of assessment instrument. The methodology used on this research is qualitative method by using content analysis based on the literature references. The results indicate that the Master Mariner is appropriate for the level 8 of Indonesian Qualification Framework. Therefore, a lecture needs to have professional experiences like Higher Vocational Education especially for Master Marine Program.
\end{abstract}

Keywords-component; IQF; master mariner; RPL

\section{INTRODUCTION}

In the context of everyday life, people carry out activities for their actual needs including learning components. Even people work in the office or at the market or at school, they all learn something related to their activities through life experiences. Learning can come in the form of formal education or non-formal education. However, the purpose is the same, how people can live together in their communities. Because of the various ways people learn, they may have different levels of competence even at the same job. Therefore, a form of recognition of their competence in the community needs to be established. Recognition of previous learning is defined as the recognition of competencies currently held by someone without consideration, regardless of how, when or where learning occurs [1]. The introduction of prior learning can be an effective way to bring or involve people into learning systems that are usually not considered from formal education and subsequently they fail to benefit from academic credentials, social status or even subsequent work [2]. Recognition of prior learning (RPL) is not only a way that students achieve fast track to a certain level of qualification, but also increases self-confidence and selfesteem [3][4].

Recognition for maritime tertiary education is also needed because it is needed for lecturers to have at least a master's degree background. Lecturers are professional educators and scientists with the main task of transforming, developing and disseminating knowledge, technology and art through education, research and community service [5]. Furthermore, lecturers must have minimum academic qualifications that graduate from master's degree programs for diploma or undergraduate programs and graduate doctoral programs for postgraduate programs [6].

The term vocational education is general in nature and covers every form of education that aims to obtain qualifications related to profession, art or certain occupations or that provide necessary training and appropriate skills and technical knowledge. Meanwhile, Vocational Education and Training (VET) qualifications have been developed with the specific aim of preparing students with skills to work. VET is designed to help people join or rejoin the workforce, move to new careers or gain additional skills in their current careers. Because it is vocational higher education, the composition of the learning process consists of units that are more practical than theoretical units. Therefore, to have the right lecturer, a professional who has experience and background in competence is needed. In society, especially for maritime vocational higher education in the master's field of marine studies, internationally recognizing marine master professionals who truly have knowledge and experience about master marines who may not have a master's degree background. Therefore, the way to recognize their professionalism in the higher education system is a challenge for the maritime community. Some even though the recognition related to prior learning and/or prior experience is quite important to be developed in the community because the community is now aware of the term recognition of prior learning (RPL).

RPL can be seen as representing a much broader and important human need for self-recognition and for building on each other as valid beings. Recognition theory proposes us a valuable way to pursue this consideration. Based on Clayton [7], we are all in the struggle for recognition that is fundamental to individual and social identity. This means that individuals need to have a social identity because it is a human need. Humans are driven by instincts toward mutual recognition, on the road to individual achievement and positive involvement in the social domain that includes recognition through personal relationships and institutional relationships and social value frameworks as suggested in [7].

Recognition of Prior Learning (RPL) for Vocational Education and Training (VET) is not well promoted because learners need high-level communication and literacy [8]. He found that the evidence requirements could be too 
burdensome and bureaucratic. One of their findings is support in the workplace, credibility of the assessor and peer encouragement.

Through RPL, individuals will obtain several benefits including alternative ways of trusted learning, when the 'normal' prerequisites used to enter have not been reached. RPL can use their previous learning that is calculated in qualifications, regardless of how or where the learning takes place. RPL will reduce the time and costs of qualifying. Through RPL, people will be recognized for their skills and abilities as certified in qualifications, allowing employers to make judgments about knowledge, skills and competencies related to certain qualifications. Furthermore, RPL is progress in qualifications that have social uses, values, and position. Furthermore, RPL will increase self-confidence and motivation. RPL will develop lifelong learning skills, specifically self-evaluation skills, self-assessment and career planning. Finally, RPL will provide access to lifelong learning pathways.

Companies involved in the recruitment of employers who have an RPL framework may have several potential benefits including encouragement for cultural development supported by lifelong training and learning, and cost reduction, less duplication of education and training, and less time spent in training. The next benefit is the encouragement for individuals to invest in their own training. In addition, the RPL will provide more effectiveness and targeted planning for training and increased employment. Finally, companies will be more effective in recruiting when labor mobility is high.

Employers also encourage recognition of prior learning because it provides a way to utilize skills that are more effective and efficient in the workforce and enable fast tracking, which means employees can become fully competent as quickly as possible. In addition, it allows skills gaps to be identified, provides a solid basis for training needs analysis and career planning and fosters a learning culture, because it builds confidence in further education and training. Finally motivate employees.

\section{METHOD}

This study aims to establish an instrument assessment that allows to recognize prior learning for marine masters to be leveled at the same level as a graduating master's degree. The methodology used in this study is a qualitative method using content analysis based on literature references. Content analysis is a research method that is applied to make conclusions that can be replicated and valid by interpreting and coding text material [9]. By systematically evaluating texts for document reports for example, qualitative data can be converted into quantitative data [10]. For example, organizational studies use this content analysis [11]. The structure of the research method is shown in Figure 1.

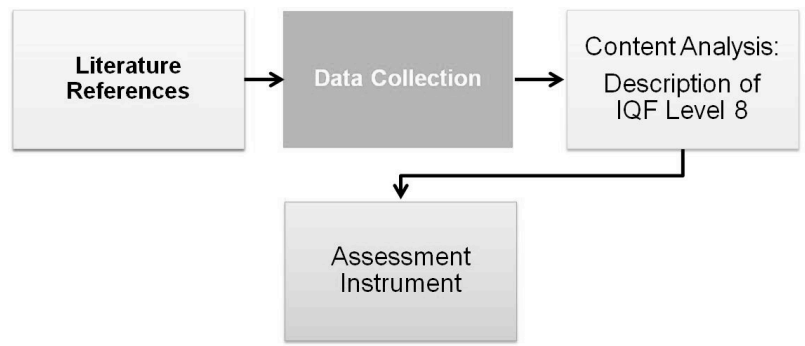

Fig. 1. Structure of Research

RPL aims to provide opportunities for the community to enter the formal education system or be equated with certain qualifications based on formal, non-formal, informal education or work experience in a very special or rare field and needed by the state such as lecturers, instructors, teachers, health workers and other specific professions that are very specific. Higher education institutions that lack lecturers in certain fields can recruit expert practitioners who do not have master's qualifications through recognition of learning outcomes from formal, non-formal, informal, and work experience in the business or industrial world. Through RPL, the adequacy of teaching staff and teachers, health workers, or other professions needed can be facilitated by the state and stakeholders. Improving the quality of Indonesia's human resources in a more competitive global competition can be supported by the Government and revised to the needs of the industrial world and the business world.

Cooperation and support from industry is an important factor for the implementation of education that is able to adapt to the needs of the workforce. Industry has an important role in providing input to the education curriculum that is in line with technological developments, provides practical facilities / internships for students / students and teachers / lecturers so that they can keep up with the latest developments in industrial technology. In addition, higher education institutions can utilize available resources in the industry to become lecturers in accordance with the qualifications and requirements set.

\section{RESUlTS AND DisCUSSION}

The benefit of the establishment of IQF is the development a system of qualification equivalence between learning outcomes acquired through education and training, work experience and self-experience with competency criteria required by a particular type of field and the level of employment. Next, it improves the recognition and equality of employment qualifications Indonesia with other countries in the world both to the learning outcomes set by the education and training institutions as well as to the competency criteria required for a particular job field and level. Further, Higher Education is organized based on the principle of a systemic unity with an open and flexible system in the learning process and the completion time of a study program. Therefore, it is very possible for cross-paths of academic, vocational or professional education (multientry and multi-exit systems). Based on this, the opportunity for the community to be able to continue formal education to 
a higher level and to make equalizations to certain qualifications can be facilitated by the Government.

The Indonesian National Qualifications Framework (IQF) is governed by Presidential Regulation Number 8 of 2012. In the regulation, article 1 paragraph (1), it is explained what the IQF is. It is a competency qualification framework that can juxtapose, equalize and integrate education and training and work experience in the framework of giving recognition of work competencies in accordance with the structure of work in various sectors. Qualification is the mastery of learning achievement which states its position in the IQF. Learning Outcomes are capabilities acquired through internalization of knowledges, attitudes, skills, competencies and accumulated work experiences. Work Experience is the experience of doing working in a particular field and a certain period of time intensively that produces competency.

Having the Presidential Regulation Number 8 of 2012, the regulation arrangements for the implementation of IQF is as follow:

A. Law of the Republic of Indonesia number 12 of 2012 concerning Higher Education.

B. Minister of Education and Culture of the Republic of Indonesia Regulation Number 73 of 2013 concerning Application of the Indonesian National Qualification Framework in the Field of Higher Education;

C. Regulation of the Minister of Education and Culture of the Republic of Indonesia Number 81 of 2014 concerning Diplomas, Competency Certificates, and Higher Education Professional Certificates;

D. Regulation of the Minister of Home Affairs of the Republic of Indonesia Number 2 of 2013 concerning Guidelines for the Development of Competency-Based on Education and Training Systems within the Ministry of Home Affairs and Regional Government;

E. Regulation of the Minister of Manpower and Transmigration, Republic of Indonesia Number 8 of 2014 concerning Guidelines for the Implementation of Competency-based on.

F. Minister of Manpower Regulation, Republic of Indonesia Number 21 Year 2014 concerning Guidelines for Implementing the Indonesian National Qualification Framework

To realize the quality and identity of the Indonesian nation in the human resources sector is linked to a national education and training system development program, the Indonesian Qualifications Framework (IQF) is one of the steps to achieve it. Every level of qualifications under the IQF has meaning and equality with learning outcomes owned by all Indonesian workers in creating quality work and contributions in their respective fields of work

In brief concept, Indonesian Qualification Framework (IQF) is the competency qualification scheme which can juxtapose, equalize and integrate between the education field and job training field, as well as work experience in the framework of granting recognition of work competencies in accordance with the work structure in various sectors [12]. In detail, the matrix of IQF is illustrated in Figure 2.

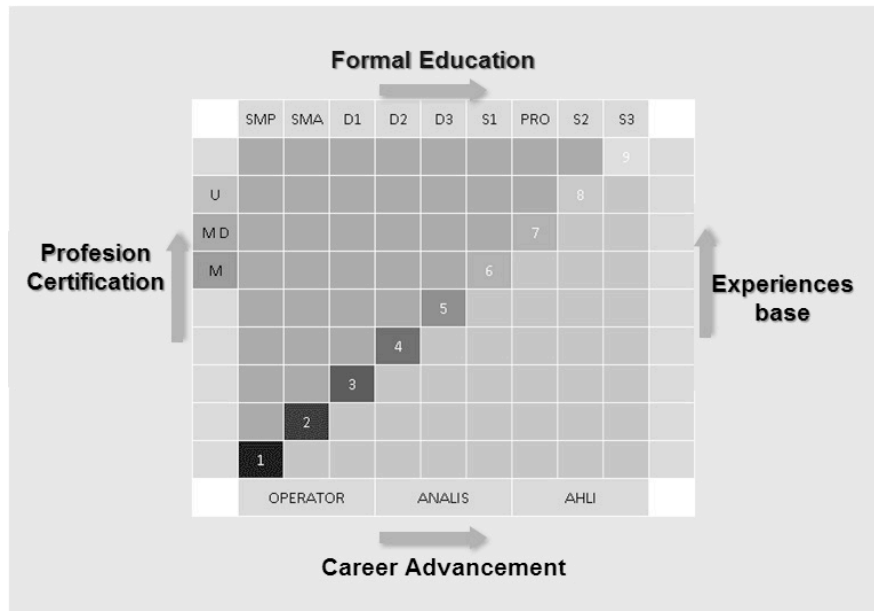

Fig. 2. Matrix of Indonesian Qualifiaction Framework

The IQF level consists of 9 levels of qualifications, started lowest level, level 1 to the highest level, level 9. The figure 2 also explain of four side of IQF such as formal education background, career advancement, profession certification and experience. It is obvious that person from experience background could be on the same level with person from formal education background. It is shown that The IQF level 8 is equivalent to a master degree and IQF level 9 is equivalent to a doctorate.

Every level of IQF level consists of 4 element achievement learning aspects which is named as descriptor such as attitudes and value, mastery of knowledge, work ability, and authority and responsibility. The element is illustrated in figure 3. Descriptors of mastery of knowledge consist of the coverage studies and branches of the science. Descriptor of work ability consists of the capabilities of the related fields, methods used, results of quality, processes / standards. While managerial abilities consist of a range of responsibilities and standards of attitude.

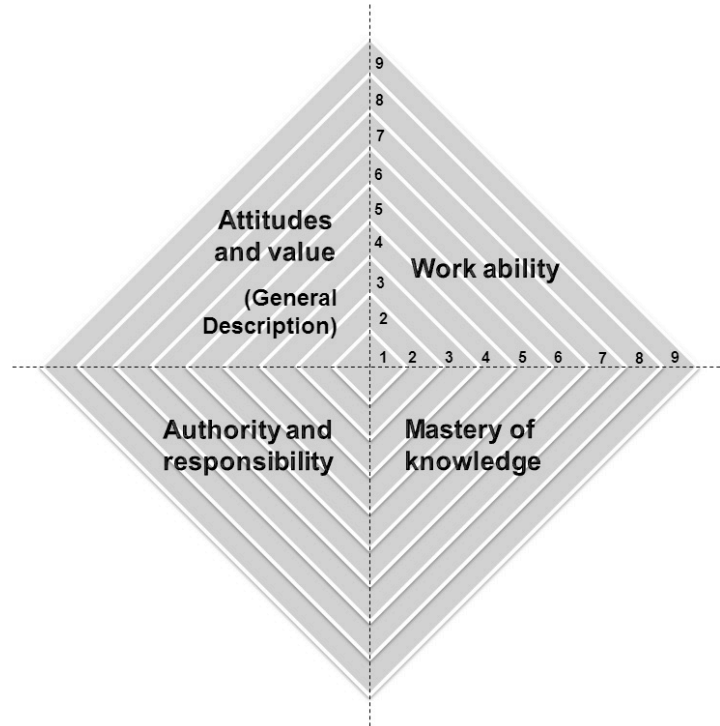

Fig. 3. Descriptor of Indonesian Qualifiaction Framework 
Based on the Minister of Research, Technology and Higher Education Regulation Number 26 of 2016 concerning Past Learning Recognition, Article 2 states that RPL is classified into 2 (two) types, namely RPL to continue formal education (type A) and RPL to obtain equality recognition with qualifications certain level of IQF (type B). The society can use RPL to continue formal education (type A) to apply for credit recognition (semester credit units / credits) for CP or work experience that they already have to continue their education to a higher level, so that they do not need to take all credits. After completing the remaining credits in college, the community can obtain a diploma

RPL to obtain recognition of equality with certain qualifications in accordance with the level of IQF (type B) can be used by universities to conduct assessments to individuals, for example to find out whether their current learning or work experience has achieved equality with $\mathrm{CP}$ in certain study programs. RPL to get recognition of equality with certain qualifications (Type B) is intended for lecturers and applicants who work in universities.

In the higher formal education background, the formal education is divided into academic and vocational root. The academic root is begun from bachelor degree up to doctoral degree. Whereas, under vocational root, it is started from Diploma 1 up to specialist 2. The detail configuration between academic and vocational root is illustrated in figure 4. It is also presented which the locating of lecturer for applied diploma IV is on the level of 8 . It requires the assessment method to qualify the qualification level of individual into level 8 . In general, the assessment method is based on the industry or professional union requirements.

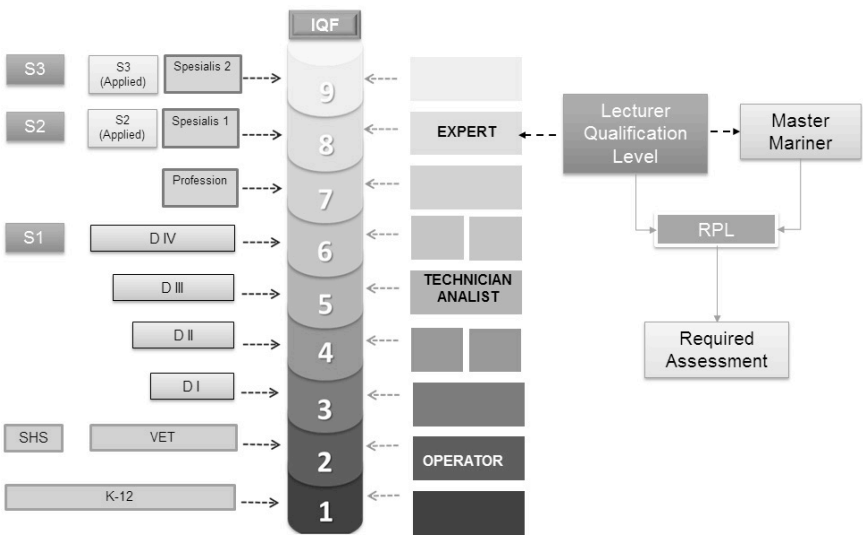

Fig. 4. Post of lecturer under IQF

Assessment is the process of collecting evidence and making judgments whether someone has achieved certain competencies or not. This confirms that an individual after learning can achieve certain competencies as expected at work, or after graduating from college. Assessor also need to be very familiar with the competencies to the point they can put aside the performance criteria and make professional judgments based on a holistic view of a candidate's abilities. Therefore, the instrument is need to be developed accordingly. The relationship between the assessor and the candidate's in perceptions of success is the participant has meant achieving a qualification or partial credit, or being able to examine skills and plan a learning program and career goals without necessarily achieving competencies. These perceptions bring to the understanding of the key success of RPL assessment is the process in which participants are treated and supported by the assessor.

RPL is a process that 'assesses the individual's learning to determine the extent to which that individual has achieved the required learning outcomes, competency outcomes, or standards for entry to, and/or partial or total completion of a qualification'. In the process of assessment, the technical knowledge and skill is primarily considered rather than generic employment attributes.

It may become a major omission during RPL process and this is contrary with the result of research which identified the importance employers and industry in general give to generic workplace competencies.

The factors affecting of successful RPL is participant trust in the assessor's interpretation of participant skills into the qualification framework, their sense of being understood and valued, and their participant of having influence upon the assessor. It was equally significant for participant to feel that they had shared their practical ability rather than simply been assessed by an assessor against a standard. To prove their competencies, the evidence is required and it may be obtained from any combination of formal or informal education and training, general life experience or work experience. The forms vary and may include certification, references from past employers, testimonials from clients and work samples. As the consequences, the evidence should be ensured authentic, valid, reliable, current and sufficient.

A master marine is a professional who is manage a ship. They are responsible for the management of whole operation of the ship. They head the deck department, engine room department and catering department. Before become a master mariner, they have study both theoretical and practical knowledge required such as seamanship, chart work, collision prevention, navigation, bridge equipment \& watchkeeping, cargo handling \& stowage, ship stability, naval architecture, meteorology, marine signaling and ship maintenance and operation. They also have the knowledge on marine engineering and catering matter.

Before post as master mariner, the career progression for a deck officer is as follows Deck Cadet, Third Officer, Second Officer, and Chief Officer. After completing sufficient time at the sea required as a deck cadet, the cadet becomes eligible to be employed as a navigating officer onboard a merchant ship. This first promotion comes with the designation of a Third Officer who responsible for safety and security of the ship. The next step promotion is as second officer who responsible for navigating matter. Then after sufficient sea time and competency certification, they may become Chief Officer who head the deck department.

To begin with the assessment instrument, the first consideration is the need of what should be done by individual regarding their task or duty. It is considered that the master marine will organize the educating and training. 
Therefore, there is 2 aspect need to be developed such as the lecturing competency professional competency field. The lecturing competency field comprises the lesson plan, carry out the learning process, and plan and implement learning assessments. The professional competency field consist of the implementation ship navigation function at the Management level, carry out the stowage and cargo handling function at the Management level, and implementation of ship operation control functions and personnel handling on ships at Management level. In detail is shown at Figure 5.

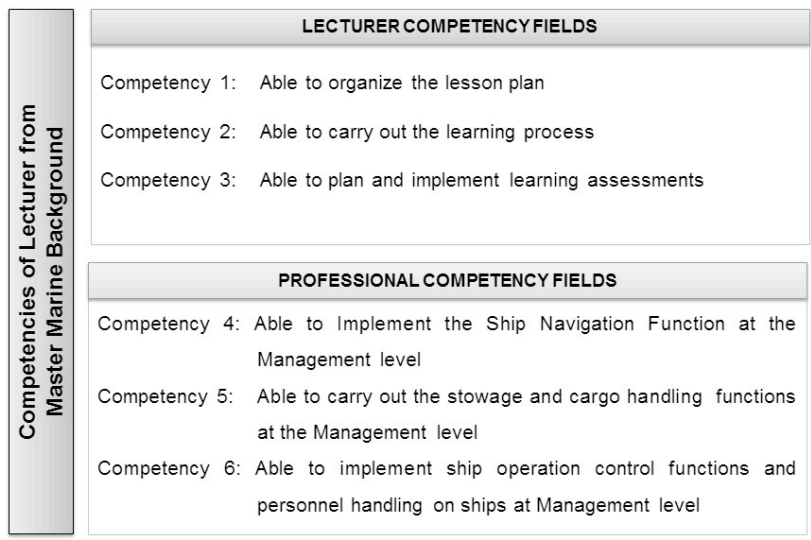

Fig. 5. Construction of Assesment Instrument

Based on the figure 5, the assessment instrument is developed into 6 competency performance indicators. As an example, table 1 illustrates the lecturing competency fields. The performance indicator is developed and qualification level is identified. The qualification level is identified from the lowest level (1) which mean the person does not have required performance at all and the highest level (5) for the person who has confidence with the required performance.

TABLE I. ASSESSMENT IINDICATOR FOR COMPETENCY 1

\begin{tabular}{|c|l|l|l|l|l|l|}
\hline \multirow{2}{*}{ No } & \multicolumn{1}{|c|}{ Performance Indicators } & \multicolumn{3}{|c|}{ Profeciency Level } \\
\cline { 3 - 7 } & \multicolumn{1}{|c|}{$\begin{array}{l}\text { Understand the learning outcomes of the } \\
\text { subjects objectives of the subjects that will be } \\
\text { delivered to students as part of the learning } \\
\text { outcomes of the study program. }\end{array}$} & & & & \\
\hline 2 & $\begin{array}{l}\text { Understand the theory of writing learning } \\
\text { outcomes based on the theory of Bloom } \\
\text { taxonomy or others. }\end{array}$ & & & & \\
\hline 3 & $\begin{array}{l}\text { Understand the subject matter / study material } \\
\text { that will be delivered to students to support } \\
\text { the learning outcomes of study programs. }\end{array}$ & & & & & \\
\hline 4 & $\begin{array}{l}\text { Make a plan for lecturing the Lesson Plan } \\
\text { Semester (RPS) }\end{array}$ & & & \\
\hline
\end{tabular}

Next example, table 2 illustrates the professional competency fields under competency 4, Able to Implement the Ship Navigation Function at the Management level. The performance indicator is developed and qualification level is identified. The qualification level is identified from the lowest level (1) which mean the person does not have required performance at all and the highest level (5) for the person who has confidence with the required performance.
TABLE II. ASSESSMENT IINDICATOR FOR COMPETENCY 5

\begin{tabular}{|c|c|c|c|c|c|c|}
\hline \multirow{2}{*}{ No } & \multirow{2}{*}{ Performance Indicators } & \multicolumn{5}{|c|}{ Profeciency Level } \\
\hline & & 1 & 2 & 3 & 4 & 5 \\
\hline 1 & $\begin{array}{l}\text { Able to plan and carry out } \\
\text { navigation and determine the } \\
\text { position of the ship and } \\
\text { analyze the accuracy of the } \\
\text { position of the ship by } \\
\text { applying the principles of } \\
\text { terresterial navigation, } \\
\text { astronomical navigation, } \\
\text { electronic navigation, } \\
\text { operating and evaluating } \\
\text { conventional electronic } \\
\text { navigation devices in the } \\
\text { watchkeeping on merchant } \\
\text { ship with tonnage of } 500 \text { GT } \\
\text { or more for all shipping areas. }\end{array}$ & & & & & \\
\hline 2 & $\begin{array}{l}\text { Able to plan and implement, } \\
\text { predict navigation due to the } \\
\text { influence of weather by } \\
\text { applying the principles of } \\
\text { maritime meteorology and } \\
\text { oceonography and analysis of } \\
\text { changes / weather predictions } \\
\text { in the navigation guard service } \\
\text { on merchant ship with tonnage } \\
\text { of } 500 \text { GT or more. }\end{array}$ & & & & & \\
\hline
\end{tabular}

\section{CONCLUSION}

The qualification of lecturer which is by regulation is set out at the level Master Degree or IQF level 8. Higher Vocational Education especially for Master Marine Programme is required more Lecturer who have professional experiences such as Master Marine. To bridge between Master Mariner qualification into IQF level 8 is required the assessment instrument. Therefore, further research needs to be carried out on the assessment model of Master Mariner recognition.

\section{REFERENCES}

[1] S. Hodge, "After competency-based training: deepening critique imagining alternatives," Int. J. Train. Res., vol. 14, no. 3, pp. 171$179,2016$.

[2] J. Garnett and A. Cavaye, "Recognition of prior learning: opportunities and challenges for higher education," 2015.

[3] J. Schut, "Recognition of prior learning in youth work in the European Union: causes for its limited use and modeling the outcomes Recognition of prior learning in youth work in the European Union: causes for its limited use and modeling the outcomes," vol. 7, no. February, pp. 263-296, 2015.

[4] H. Pokorny and H. Pokorny, "Assessing prior experiential learning : issues of authority, authorship and identity," 2012.

[5] Hartoyo, D. Laras, and Soenarto, "Survey on Integration of Expetise Competency Test Into Teacher Certification Program of Productive Vocational Teachers Survey on Integration of Expetise Competency Test Into Teacher Certification Program of Productive Vocational Teachers," 2018.

[6] E. Doxtader, "Question The Recognizability of Recognition: Fragments in the Name of a Not Yet Rhetorical Question," vol. 48, no. 4, pp. 379-412, 2016

[7] B. Clayton, Recognising non-formal and informal learning : Participant insights and perspectives. NCVER, 2009.

[8] K. Krippendorff, Content analysis: An introduction to its 
methodology, Fourth Edi. London: SAGA Publication, Inc., 2018.

[9] University of Georgia, "Content Analysis site. Retrieved from https://www.terry.uga.edu/management/contentanalysis/resources/." 2012.

[10] S. Gold, S. Seuring, and P. Beske, "Sustainable Supply Chain Management and Inter-Organizational Resources: A Literature Review," vol. 245, no. July 2009, pp. 230-245, 2010.

[11] Republic Indonesia Government, "Law of the Republic of Indonesia number 12 of 2012 concerning Higher Education," pp. 1-8, 2012.

[12] P. Wheelahan, L, Miller, P., Newton, D, Dennis, N, Firth, J., Pascoe, S $\&$ Veenker, Recognition of Prior Learning: policy and practice in Australia, report to Australian Qualifications Framework Advisory Board. United States: IGI Global, 2016. 